\title{
Thermal Behavior Improvement of Fortified Commercial Avocado (Persea americana Mill.) Oil with Maqui (Aristotelia chilensis) Leaf Extracts
}

\author{
Marcos Flores ${ }^{1, *(D)}$, Luis Reyes-García ${ }^{1}\left(\mathbb{D}\right.$, Jaime Ortiz-Viedma ${ }^{2} \mathbb{D}$, Nalda Romero $^{2}$, Yesica Vilcanqui ${ }^{3} \mathbb{D}$, \\ Cristian Rogel ${ }^{4}$, Javier Echeverría ${ }^{5}$ (D) and Oscar Forero-Doria ${ }^{5, *(D)}$
}

1 Departamento de Ciencias Básicas, Facultad de Ciencias, Universidad Santo Tomás, Talca 3460000, Chile; luisreyesga@santotomas.cl

2 Departamento de Ciencia de los Alimentos y Tecnología Química, Facultad de Ciencias Químicas y Farmacéuticas, Universidad de Chile, Casilla 233, Santiago 8320000, Chile; jaortiz@uchile.cl (J.O.-V.); nromero@uchile.cl (N.R.)

3 Escuela de Ingeniería Agroindustrial, Universidad Nacional de Moquegua, Prolongación Calle Ancash S/N, Moquegua 18001, Peru; yvilcanquic@unam.edu.pe

4 Departamento de Ciencia y Tecnología de los Alimentos, Facultad de Farmacia, Universidad de Concepción, Concepción 4030000, Chile; crogel@udec.cl

5 Departamento de Ciencias del Ambiente, Facultad de Química y Biología Universidad Santiago de Chile, Santiago 9170022, Chile; javier.echeverriam@usach.cl

check for updates

Citation: Flores, M.; Reyes-García, L.; Ortiz-Viedma, J.; Romero, N.; Vilcanqui, Y.; Rogel, C.; Echeverría, J.; Forero-Doria, O. Thermal Behavior Improvement of Fortified Commercial Avocado (Persea americana Mill.) Oil with Maqui (Aristotelia chilensis) Leaf Extracts. Antioxidants 2021, 10, 664. https:// doi.org/10.3390/antiox10050664

\section{Academic Editors:}

Costantino Paciolla, Martina Loi and Simone Carradori

Received: 17 March 2021

Accepted: 22 April 2021

Published: 24 April 2021

Publisher's Note: MDPI stays neutral with regard to jurisdictional claims in published maps and institutional affiliations.

Copyright: () 2021 by the authors. Licensee MDPI, Basel, Switzerland. This article is an open access article distributed under the terms and conditions of the Creative Commons Attribution (CC BY) license (https:// creativecommons.org/licenses/by/ $4.0 /)$.
* Correspondence: marcosflores@santotomas.cl (M.F.); oscar.forero@usach.cl (O.F.-D.); Tel.: +56-712-342-418 (M.F.)

Abstract: Avocado oil is considered a highly prized food due to its nutritional contribution. On the other hand, Aristotelia chilensis (Molina) Stuntz (Elaeocarpaceae), common name "maqui", is an endemic fruit in Chile, well known for its exceptional antioxidant properties. In general, maqui by-products such as leaves are considered as waste. Thus, maqui leaves extracts were used to improve the stability of vegetable oils, particularly avocado oil. Hence, avocado oil was fortified with two extracts (ethyl ether and methanol) obtained of maqui leaves and exposed to $120^{\circ} \mathrm{C}$ for $386 \mathrm{~h}$ in an oven. The results showed a high content of monounsaturated fatty acids $(69.46 \%$, mainly oleic acid), followed by polyunsaturated fatty acids ( $16.41 \%$, mainly linoleic acid) and finally saturated fatty acids $(14.13 \%)$. The concentration of the total phenolic compounds in the pure oil, ethyl ether and methanol maqui leaves extracts were $45.8,83.7$, and $4100.9 \mathrm{ppm}$, respectively. In addition, the antioxidant activity was 5091.6 and 19,452.5 $\mu \mathrm{mol}$ Trolox eq/g for the ethyl ether and methanol extracts, respectively. The secondary degradation compounds showed significant differences between the fortified and non-fortified samples after $144 \mathrm{~h}$ and the TG/DTG analysis showed a significant increment of $7^{\circ} \mathrm{C}$ in the degradation temperature (Tonset) of avocado oil fortified with the methanol extract when compared to the non-fortified oil and fortified oil with ethyl ether extract. After heating for $336 \mathrm{~h}$, fortified oil with methanol extract reached the limit percentages of polar compounds, while pure oil reached it in a shorter time, i.e., $240 \mathrm{~h}$. Based on the results, avocado oil can be protected with natural additives such as extracts obtained from maqui leaves, leading to an increase in its thermo-oxidative stability.

Keywords: avocado oil; thermo-oxidative stability; maqui leaf extracts; polar compounds; antioxidant activity

\section{Introduction}

The use and consumption of avocado oil has increased in the last decade due to the positive effects in areas such as health, cosmetics, and technology [1]. Avocado oil has a high content in oleic acid as well as a low content in saturated fatty acids. For this reason, it is preferred in diets to reduce cardiovascular diseases [2]. Avocado oil is characterized by a 
low concentration of saturated fatty acids (10-19\%), which depends on its state of maturity, variety, and geographical origin [3,4]. In addition, it has a high concentration of oleic acid $(>80 \%)$ and an acceptable level of polyunsaturated fatty acids (11-15\%) [2,5]. Moreover, avocado oil has a high concentration of $\beta$-sitosterol, vitamin E, $\alpha$-tocopherol, and low amounts of squalene, aliphatic, and terpenic alcohols, and other unsaponifiable compounds with biological activity [6]. Unlike industrially refined vegetable oils which are fortified with synthetic antioxidants such as hydroxybutylanisol (BHA), butylhydroxytoluene (BHT) and tert-butylhydroquinone (TBHQ), are usually added to extend the shelf life of edible oils $[7,8]$. Avocado oil is marketed mainly as an unrefined oil, avoiding the use of synthetic components, which are often questioned due to possible negative health effects [1,9]. However, due to lipid deterioration processes such as thermo-oxidation, it is necessary to find safe, effective, and innocuous antioxidants.

In the field of Food Science, an important challenge is to improve the shelf life of edible oils, due to the susceptibility to oxidation, especially when edible oils undergo heating processes. So far, there has been little interest in the thermo-oxidative behavior of avocado oil in different deterioration conditions [10-12]. Therefore, the study and use of plant byproducts or natural extracts to improve the stability of edible oils or lipid matrices, to avoid using synthetic antioxidants, is becoming increasingly stronger. For instance, the following plants extracts have been used to improve the stability of edibles oils: Rosehip extracts to improve the thermo-oxidative deterioration of grapeseed oil; methanolic extracts of barley seeds to improve the stability of sunflower oil; and carotenoids obtained from dried tomato residues were applied during the thermo-oxidation of different edible oils [13-15].

However, there is a lack of research related to the possible effect of native species coming from South America such as Aristotelia chilensis (Molina) Stuntz (Elaeocarpaceae), common name "maqui", on the thermo-oxidative stability of edible oils such as avocado oil. Maqui is known worldwide for its extraordinary antioxidant properties found mainly in the fruit [16]. Recently, some benefits and applications of the maqui fruit have been reported, e.g., beneficial postprandial effects after the consumption of the maqui fruit in healthy individuals, antioxidant and antibacterial effects of the maqui fruit present in coatings for food use, preparation of microparticles from the juice of the maqui fruit, among other applications [17-19]. On the other hand, it has been discovered that the leaves of the maqui berry have important analgesic, anti-inflammatory, antioxidant [20], antiviral [21], and $\alpha$-glucosidase inhibitory activities [16].

To our knowledge, there is no information available about the use of maqui byproducts such as maqui leaves and their use as an additive in edible oils [22]. Thus, the main objective of this research is to study the thermo-oxidative behavior of fortified avocado oil with two maqui leaves extracts.

\section{Materials and Methods}

\subsection{Reagents}

The Folin-Ciocalteu reagent, gallic acid, phosphate buffer solution, Trolox, standard fatty acid methyl esters (FAMEs), and other chemicals (analytical grade) were purchased from Merck (Santiago, Chile).

\subsection{Plant Materials}

Extra virgin avocado oil was purchased from a local store. Aristotelia chilensis (Molina) Stuntz (Elaeocarpaceae) leaves of at least $8 \mathrm{~cm}$ in length were collected from wild trees located in the Maule Valley, Maule Region of Chile $\left(35^{\circ} 25^{\prime} 36^{\prime \prime}\right.$ S $71^{\circ} 39^{\prime} 58^{\prime \prime}$ W). Maqui leaves were selected by simple random sampling, where three samples of at least $2 \mathrm{~kg}$ were obtained. Then, maqui leaves were reduced in sample size by quartering. About $1000 \mathrm{~g}$ of $A$. chilensis leaves were air-dried in an oven dryer model UF-55 (Memmert, Schwabach, Germany) at $50{ }^{\circ} \mathrm{C}$ for $24 \mathrm{~h}$. Then, they were ground to obtain a powder that passes through a $2 \mathrm{~mm}$ sieve, packed in polyethylene bags coated with aluminum, and stored under ambient conditions for later analysis and use. 


\subsection{Preparation of Extracts from Maqui Leaves}

Twenty grams of ground maqui leaves (10 mesh size) were placed in a $250 \mathrm{~mL}$ flask and mixed with $150 \mathrm{~mL}$ of $100 \%$ methanol and $150 \mathrm{~mL}$ of ethyl ether. The extraction was performed on an orbital shaker model NB-101M, (N-Biotek, Bucheon, Korea) for $48 \mathrm{~h}$ under ambient conditions (stirring intensity $200 \mathrm{rpm}$ ). Then, the extraction solution was filtered through a filter paper (Whatman No 1). Next, the solid residues were re-extracted twice with $150 \mathrm{~mL}$ of new solvent (i.e., methanol and ethyl ether) each time and the extracts were pooled. The methanol (M) and ethyl ether (E) extracts of maqui leaves were concentrated to dryness under reduced pressure at $45^{\circ} \mathrm{C}$, using a rotary evaporator.

\subsection{Thermal Analysis}

Oil analysis for enriched and non-enriched samples was performed on a TGA-Q500 thermogravimetric analyzer (TA-instruments, Hertfordshire, UK). The temperature range for this study was from room temperature to $700{ }^{\circ} \mathrm{C}$. The furnace heating rate was $5{ }^{\circ} \mathrm{C} \cdot \mathrm{min}^{-1}$ with a controlled mass flow of air of $60 \cdot \mathrm{mL} \mathrm{min}^{-1}$ as reagent gas. Additionally, $\mathrm{N}_{2}$ with a flow of $40 \mathrm{~mL} \cdot \mathrm{min}^{-1}$ was used as protective gas. The sample mass placed in a platinum crucible (Pt) inside the balance was around $10 \mathrm{mg}$ for each analysis. Subsequently, the thermogravimetry (TG) and differential thermogravimetry (DTG) curves were analyzed.

\subsection{Thermooxidation Test and Sampling Period}

Four hundred grams of pure, unfortified avocado oil (OP), avocado oil enriched with methanol extract of maqui leaves $(\mathrm{OM})$, and avocado oil enriched with ethyl ether extract of maqui leaves (OE) were added to different 500 -mL glass beakers and heated at $120 \pm 1{ }^{\circ} \mathrm{C}$ in the oven (UF-55) for $386 \mathrm{~h}$. Fortified oils were prepared at a concentration of $800 \mathrm{ppm}$ based on an oxidative stability study of different additives on lipid matrices [23]. Samples were collected and analyzed every $72 \mathrm{~h}$ until reaching 386 total hours. Analyses were conducted in triplicate.

\subsection{Analytical Determinations}

\subsubsection{Total Phenolic Content (TPC)}

The total phenolic content was determined by the Folin-Ciocalteu reagent according to the method proposed by Chun et al. (2005) with minor modifications [24]. The absorbance was measured at $765 \mathrm{~nm}$ in a UV/VIS UV3-200 model ATI Unicam spectrophotometer (UNICAM, Cambridge, UK). Gallic acid solutions were used for the calibration curve with six points. The results were expressed in $\mathrm{mg} \mathrm{GAE} / \mathrm{kg}$ of sample.

\subsubsection{Antioxidant Capacity: ORAC Assay}

The antioxidant capacity of the samples was carried out as described by Dávalos et al. (2004) with some modification [25]. A 0.075M phosphate buffer solution ( $\mathrm{pH} 7.0)$ was prepared, then a stock solution of fluorescein was prepared by dissolving $0.0038 \mathrm{~g}$ of fluorescein in $10 \mathrm{~mL}$ of buffer (solution 1), a second stock solution was prepared by diluting $100 \mu \mathrm{L}$ in $1 \mathrm{~mL}$ of buffer (solution 2), and $100 \mu \mathrm{L}$ of solution 2 was added to $10 \mathrm{~mL}$ of phosphate buffer (solution 3). A Trolox $1 \mathrm{mM}$ standard was prepared, and from the Trolox stock solution, an aliquot of $50 \mu \mathrm{L}$ was taken. In $450 \mu \mathrm{L}$ of phosphate buffer, this solution was divided into aliquots in small vials to perform the Trolox calibration curve $(10,20,30$, $40,50,60 \mu \mathrm{M})$ in phosphate buffer in appropriate wells. For the analyses, 96 -well black microplates were used in which excitation $(485 \mathrm{~nm}) /$ emission $(538 \mathrm{~nm})$ was produced from the top of the dish. The buffer solution was utilized as a blank to dilute the samples. To perform the ORAC analysis, $25 \mu \mathrm{L}$ of the diluted sample containing the phenolic compounds, $150 \mu \mathrm{L}$ of fluorescein were added to the 96-well black plate, the microplate was incubated for $30 \mathrm{~min}$ at $37^{\circ} \mathrm{C}$, and then the reaction was initiated by the addition of $25 \mu \mathrm{L}(75 \mathrm{mM})$ of AAPH (2,2'-Azobis (2-methyl-propionamidine) dihydrochloride). 
Readings were obtained from a microplate reader model synergy HTX (Biotek, Winooski, VT, USA). The antioxidant capacity was expressed as $\mu$ Meq Trolox/g of sample.

\subsubsection{Gas Chromatography Coupled with Flame Ionization Detector (GC/FID)}

Fatty acid profile was obtained for avocado oil by using fatty acid methyl esters derivatives and analyzed by gas chromatography coupled to a flame ionization detector (Hewlett-Packard, Palo Alto, CA, USA), equipped with a split-splitless injector. The separation of the different fatty acid methyl esters was done in a capillary column BPX70 (50 m length, $0.32 \mathrm{~mm}$ internal diameter, $0.25 \mu \mathrm{m}$ film thickness; SGE, Melbourne, Australia). The carrier gas was hydrogen at a flow rate of $1 \mathrm{~mL} \cdot \mathrm{min}^{-1}$. The conditions for the oven were as follows: The initial temperature was set to $160{ }^{\circ} \mathrm{C}$ with a temperature gradient from 180 to $230{ }^{\circ} \mathrm{C}$ at $2{ }^{\circ} \mathrm{C} \cdot \mathrm{min}^{-1}$. The sample size was $1 \mu \mathrm{L}$. The identification of the fatty acids was done by comparison of their retention times with those of standard fatty acid methyl esters (FAME) from Merck (Merck, Darmstadt, Germany) [26].

\subsection{Specific Extinction Coefficient ( $k_{270}$ and $k_{232}$ ) of Avocado Oil}

The extinction coefficient $\left(k_{270}\right.$ and $\left.k_{232}\right)$ was determined following the protocol proposed by Antolin and Meneses (2000) with minor modifications [27]. Specifically, avocado oil samples were diluted in n-hexane to obtain a $1 \%(w / v)$ solution. Then, the oil samples were measured using quartz cuvettes with pure solvent as a reference. Absorption measures were taken at $k_{232}$ and $k_{270} \mathrm{~nm}$ in a UV spectrophotometer (PG Instruments T80 + UV-visible spectrometers). The values of $k$ were calculated according to Equation (1):

$$
\mathrm{k} \lambda=\operatorname{Abs} \lambda / \mathrm{D} \times \mathrm{L}
$$

where Abs $\lambda$ is the absorption, $\mathrm{D}$ is the dilution expressed in $\mathrm{g} / 100 \mathrm{~mL} ; \mathrm{L}$ is the cuvette pathlength $(1 \mathrm{~cm}$ path); and $\mathrm{k} \lambda$ is the specific extinction coefficient at different wavelengths.

\subsection{Calculated Oxidizability Value (Cox Value)}

The Cox value of the oil was calculated based on the sum of the percentages of unsaturated fatty acids multiplied by proportionality factors, applying the formula proposed by Fatemi and Hammond (1980) [28].

$$
\text { Cox value }=[1 \times(16: 1 \%+18: 1 \%)+10.3 \times(18: 2 \%)+21.6 \times(18: 3 \%)] / 100
$$

\subsection{Total Polar Compounds}

The percentage of polar compounds was determined with the use of an electrochemical sensor model Testo 270 (Testo AG, Lenzkirch, Germany). The instrument conditions were those indicated by the manufacturer. Briefly, once the oil samples were removed from the oven to carry out the different physical-chemical analyses (around $30 \mathrm{~mL}$ ), the testo sensor was immediately introduced into the solution, respecting the time required for a stabilized reading. Polar compounds were expressed as percentages.

\subsection{Statistical Analysis}

A one-way ANOVA was performed to determine if there were statistically significant differences between the samples (fortified and non-fortified oils). The comparison of means was made using the least significant difference (LSD) method using IBM SPSS Statistics Version 19 (International Business Machines Co., Armonk, NY, USA). The differences between samples were considered significant for a confidence interval at the $95 \%$ level $(p<0.05)$ in all cases.

\section{Results and Discussion}

Table 1 shows the fatty acid profile of avocado oil, which is mainly monounsaturated fatty acids (oleic acid $>65 \%$ ) followed by a lower proportion of polyunsaturated fatty acids (16.41\%) and saturated fatty acids (14.13\%). Thus, avocado oil has a polyunsatu- 
rated/saturated ratio $(\mathrm{P} / \mathrm{S})$ equal to 1.16 and a Cox value of 2.53 . These values demonstrate the oxidation susceptibility of avocado oil, which is slightly higher than those for other vegetable oils such as olive oil [29]

Table 1. Fatty acids profile of avocado oil.

\begin{tabular}{|c|c|}
\hline Fatty Acid & Percentage $(\%)$ \\
\hline C14:0 & $0.054 \pm 0.001$ \\
\hline C16:0 & $13.512 \pm 0.001$ \\
\hline $\mathrm{C} 16: 1 \omega 9 \omega 7$ & $5.398 \pm 0.004$ \\
\hline $\mathrm{C} 18: 0$ & $0.474 \pm 0.001$ \\
\hline C18:1 $\omega 9$ & $55.954 \pm 0.056$ \\
\hline C18:1 $\omega 7$ & $7.222 \pm 0.060$ \\
\hline $\mathrm{C} 18: 2$ & $16.127 \pm 0.012$ \\
\hline C20:0 & $0.062 \pm 0.002$ \\
\hline C18:3 & $0.935 \pm 0.003$ \\
\hline C20:1 & $0.170 \pm 0.003$ \\
\hline C22:0 & $0.031 \pm 0.002$ \\
\hline C24:0 & $0.056 \pm 0.004$ \\
\hline Total Saturated & 14.190 \\
\hline Total Monounsaturated & 68.747 \\
\hline Total Polyunsaturated & 17.062 \\
\hline Polyunsaturated/Saturated (P/S) & 1.202 \\
\hline Unsaturated/Saturated (U/S) & 6.047 \\
\hline
\end{tabular}

In general, edible oils used in food are rich in unsaturated fatty acids, mainly linoleic acid from corn [30], soybean [31], and sunflower [31], and oleic acid from canola (60.7\%) [32], avocado (65.3\%) [10], and olive (66.4-81.5\%) [33,34]. Non-conventional oil sources such as jerivá [35], araça [36], and coffee (Arabica and Robusta varieties) [37,38] are also predominantly high in unsaturated fatty acids.

The fatty acid profile of avocado oil reported in previous studies shows a traditional composition range from highest to lowest proportion in the following order; oleic (C18:1) 60-80\%, palmitic (C16:0) 10-25\%, linoleic (C18:2) 7-20\%, palmitoleic (C16:1) 2-8\%, stearic (C18:0) $0.1-1.5 \%$, and linolenic (C18:3) $0.2-1.0 \%$ acids $[39,40]$. The differences in linolenic acid composition from the avocado oil obtained from Chile with other geographical regions were $\Delta C 18: 3=0,26$. The percentages of linolenic and linoleic acids decrease at higher temperatures. This decrease is accompanied by an increase in oleic acid [41].

Recently, others range have been reported for fatty acids from several avocado oils, which include increasing the proportion of unsaturated fatty acids, and therefore their predisposition to oxidation: Palmitic at 10.0-35.2\%; palmitoleic at 2.8-16.1\%; stearic at $0.2-1.5 \%$; oleic at 36.9-74\%; linoleic at $6.1-21.2 \%$; and linolenic at $0.3-2.1 \%$. In addition, the presence of $\omega 7, \omega 9$, and $\omega 11$ isomers of oleic and palmitoleic acids in avocado oil has been described [42]. During the oxidation of edible oils at high temperatures $\left(>100{ }^{\circ} \mathrm{C}\right)$, it has been shown that polyunsaturated fatty acids have a higher degradation rate, followed by monounsaturated fatty acids and finally saturated fatty acids [43]. On the other hand, compounds found in edible oils, such as tocopherols and tocotrienols, decrease dramatically as deterioration is prolonged ( $<30 \%$ at the initial concentration) [13]. It is essential to know the proportion of each group of compounds and the relationship between them because it will define the oxidation susceptibility of the edible oil. For example, the P/S ratio is related to the oxidation susceptibility. In this case, the value presented by the avocado oil (1.20) is similar to Chilean hazelnut oil (1.16), which has been shown to have an adequate thermal stability [44].

In Figure 1A, the evolution of the absorption coefficient $k_{232}$ of the OP, OM, and OE samples exposed to $120{ }^{\circ} \mathrm{C}$ for $336 \mathrm{~h}$ is shown. In general, an increase in this parameter is observed in all samples as the heating time increases. Significant differences of the $k_{232}$ 
value at $144 \mathrm{~h}$ of $\mathrm{OP}\left(68.95 \pm 0.67,{ }^{* *} p<0.01\right)$, with respect to $\mathrm{OE}$ and $\mathrm{OM}$ oils, are observed (Figure 1B).

A

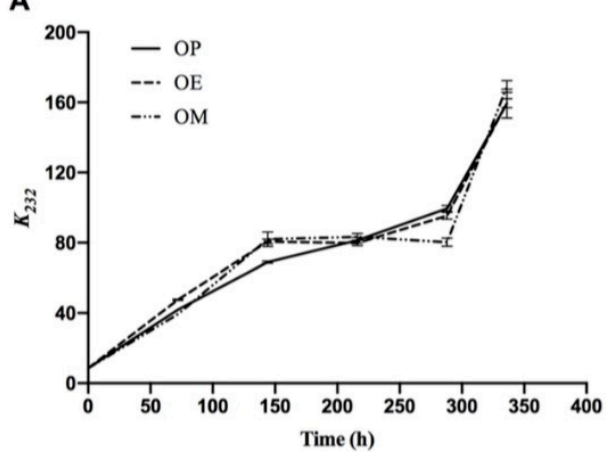

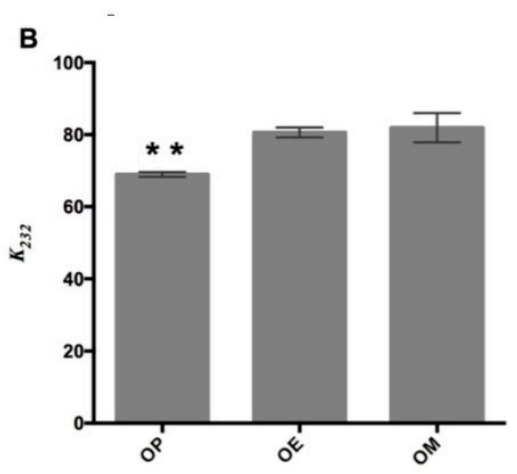

Figure 1. Evolution of primary oxidation compounds during the thermo-oxidation of avocado oil $(\mathrm{OP})$, avocado oil fortified with methanolic (OM), and ethyl ether (OE) maqui extracts. (A) evolution of $k_{232}$ as time increases, (B) statistical analysis of the $k_{232}$ value at $144 \mathrm{~h}$. OP: avocado oil. ${ }^{* *} p<0.01$ with respect to $\mathrm{OE}$ and $\mathrm{OM}$ oils.

The same trend has been documented during the thermo-oxidation of different edible oils. It has been correlated with an increase in the concentration of primary oxidation compounds and therefore the quality of the oils [27]. The curves for OP, OM, and OE showed no significant differences. Therefore, the oil fortified with the $\mathrm{OM}$ and $\mathrm{OE}$, respectively, did not have a protective effect against the formation of primary oxidation products (namely, peroxides and hydroperoxides with conjugated double bonds) compared to OP. Primary oxidation products are known to be unstable during thermo-oxidative deterioration. These by-products are rapidly transformed into secondary oxidation products such as aldehydes, ketones, and alcohols [45].

Regarding the absorption coefficient $k_{270}$, which is shown in Figure $2 \mathrm{~A}$, a separation of the curves (OP, OE, and $\mathrm{OM}$ ) can be observed after heating for $140 \mathrm{~h}$, with a significant difference of the values of $k_{270}\left(p<0.05 ; p=5.8 \times 10^{-12}\right)$ at $144 \mathrm{~h}$. The OP oil showed the highest $k_{270}$ value with significant differences at $144 \mathrm{~h}\left(92.96 \pm 0.14,{ }^{* *} p<0.01\right)$, while $\mathrm{OE}$ and $\mathrm{OM}$ oils showed $k_{270}$ value of $77.55 \pm 0.13(p<0.05)$ and $78.09 \pm 0.05$ (Figure 2B), respectively. On the other hand, OP showed significant differences at $336 \mathrm{~h}$ $\left(178.03 \pm 0.42,{ }^{* * * *} p<0.0001\right)$ with respect to $\mathrm{OE}$ and $\mathrm{OM}$ with $k_{270}$ values of $145.08 \pm 0.18$ and $132.16 \pm 0.15$, respectively. As is observed, there is an approximate decrease of 18 and $26 \%$ of $k_{270}$ values of $\mathrm{OE}$ and $\mathrm{OM}$, making the methanol extract of maqui leaves (M) a better antioxidant.
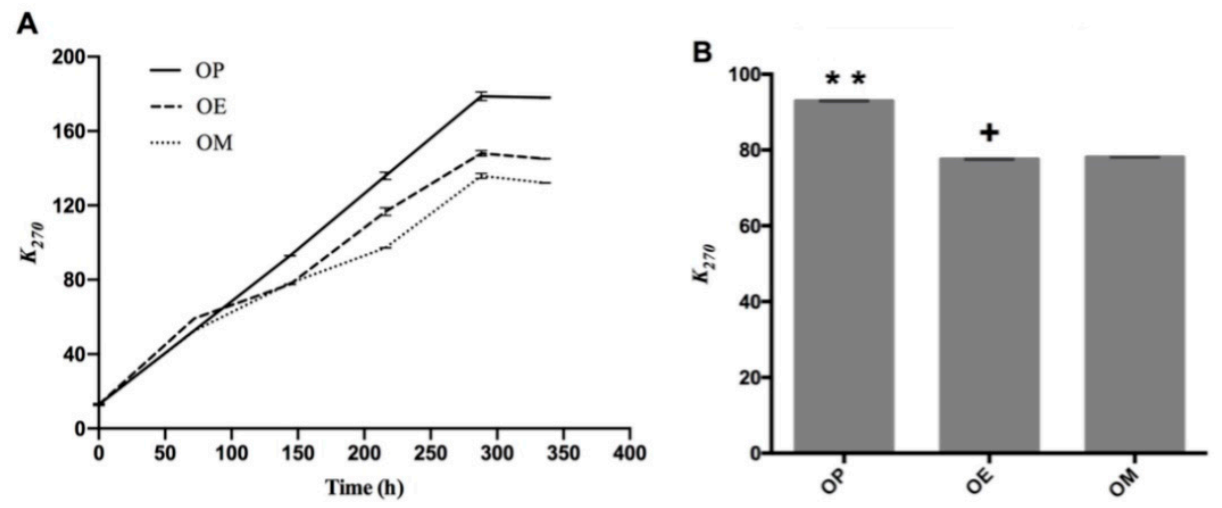

Figure 2. Secondary oxidation compounds during the thermo-oxidation of avocado oil (OP), avocado oil fortified with methanolic (OM) and ethyl ether (OE) maqui extracts. (A) evolution of $k_{270}$ as time increases, (B) statistical analysis of the $k_{270}$ value at 144 and $336 \mathrm{~h}$. OP: avocado oil. ${ }^{* *} p<0.01$, with respect to $\mathrm{OE}$ and $\mathrm{OM}$ oils and $+p<0.05$ of $\mathrm{OE}$ with respect to $\mathrm{OP}$ and $\mathrm{OM}$. 
This increase can be explained by the presence of oxygen in the oven due to the wide contact area $\left(52.8 \mathrm{~cm}^{2}\right)$ between the lipid mass and the air mass above the oils. On the other hand, ethyl ether (E) and methanol (M) extracts of maqui leaves exert an antioxidant effect in the avocado oil reducing the $k_{270}$ value in 15.41 and $14.87 \%$, respectively.

In a previous work, samples of commercial avocado oil from Chile showed $k_{270}$ values of $0.72 \pm 0.01$ and $0.17 \pm 0.003$, and $k_{232}$ values of $4.19 \pm 0.09$ and $3.16 \pm 0.06$ at $25^{\circ} \mathrm{C}$ [40]. Avocado oil samples from Mexico have shown $k_{232}$ values in the range between 0.31-1.06, $k_{268}$ in the range from $0.017-13$, and $k_{274}$ between $0.013-0.12$ [46] at room temperature. Recently, Resende et al. [47] reported that the $k_{232}$ and $k_{270}$ values in avocado oil increased linearly at a higher rate, becoming constant or decreasing after a short reaction time at high temperatures.

Our results are in agreement with the observations of Resende et al. (2019) [47] where $k_{232}$ and $k_{270}$ values increased linearly at a higher rate with increasing time at study temperature $\left(120^{\circ} \mathrm{C}\right)$. The OP curve after $144 \mathrm{~h}$ continues with sustained increase and greater than the curves for OE and OM until the end of the heating period ( $336 \mathrm{~h})$. The results show that the methanol extract had the best performance against the production of secondary oxidation compounds, producing a lower number of secondary compounds after around $100 \mathrm{~h}$ of heating.

The protective effect for avocado oil fortified with the ethyl ether extract and the methanol extract can be attributed to the addition of phenolic compounds present in them. According to Table 2, it can be seen that OM has a total phenolic content greater than 40 times than OE. A greater protective effect from OM can be explained by the higher content of total phenols compounds present in the extract due to the affinity of the phenolics compounds with the polarity of the solvent. OM and OE extracts exhibited an antioxidant capacity of 19,452.5 \pm 2111.1 and $5091.6 \pm 174.6$, respectively, expressed as $\mu$ mol Trolox eq/g dry wt.

Table 2. Total phenolic content (TPC) and antiradical capacity (AC) of OP, OE, and OM samples.

\begin{tabular}{cccc}
\hline Sample & OP & OE & OM \\
\hline TPC (ppm GAE) & $45.8 \pm 3.9$ & $83.7 \pm 9.8$ & $4100.9 \pm 212.6$ \\
AC $(\mu$ mol Trolox eq/g dry wt. $)$ & nd & $5091.6 \pm 174.7$ & $19,452.5 \pm 2111.1$ \\
\hline nd. No determined. & & &
\end{tabular}

Previous studies in samples of two commercial avocado oils from Chile showed a total phenolic content (TPC) of $42.6 \pm 1.1$ and $56.9 \pm 0.9 \mathrm{mg} / \mathrm{Kg}$ [40], while samples from South Africa had a total phenolic content of $0.58 \pm 0.66 \mathrm{mM}$ TAEC $/ \mathrm{kg}$ [48]. The sample from Mexico showed a TPC between $0.51-11.77 \mathrm{mg} / \mathrm{g}$ and ORAC values between 28.24-65.92 $\mathrm{mol} / \mathrm{Kg}$ [46].

Jiménez et al. (2017) [49] reported the effects of hydroalcoholic extracts of olive leaf (OHE) on the thermal stability of two mainly monounsaturated vegetable oils such as canola oil (CO) and high oleic sunflower oil (HOSO), both with over $50 \%$ monounsaturated fatty acids, during French potatoes frying at $180^{\circ} \mathrm{C}$. The fortification of the extract in both oils decreased the formation of polar compounds, this protective phenomenon can be attributed to the compounds present in the extract such as oleuropein and its derivatives, oleuroside and oleuroside-10-carboxylic acid.

Sun-Waterhouse et al. (2011) [50] investigated the effects of specific phenolic compounds on the thermal stability of avocado and coconut oils at various temperatures with a maximum of $60^{\circ} \mathrm{C}$. The incorporation of phenolic compounds during prolonged storage protects the degradation of unsaturated fatty acids; however, hydrolysis of triacylglycerols has been demonstrated. Other studies demonstrate the nutritional benefits of fortifying avocado oil with encapsulated antioxidant compounds such as floridzin, at medium temperatures such as $37^{\circ} \mathrm{C}$ [51]. However, it is necessary to deepen its behavior at high temperatures to bring the research closer, for example, to the cooking and food preparation processes as proposed in this study. 
The AC value obtained for the OM is approximately four times greater than OE. These results are related to the higher affinity of the antioxidant compounds for the more polar solvent, which is in accordance with the total phenolic content for each extract. The values reported in this study are higher than those obtained for other wild fruits calculated by the ORAC method, which ranged from 519.2 to $854.8 \mu \mathrm{mol}$ Trolox Eq/g dry $\mathrm{wt}$. The results may be related to a marked protective effect of extracts from the maqui tree leaves [52]. In the literature, it has been described that extracts from solvent mixtures of high polarity (ethanol/water) of maqui leaves have phenolic components such as phenolic acids, flavonoids, anthocyanins, flavanols, and stilbenes, as well as alkaloids and phytosterols, which also have antioxidant activity [53,54]. In addition, extracts of different polarities of the maqui have shown interesting results for antioxidant activity, antibacterial capacity, and a protective effect in a lipid model due to the phenolic composition of leaves $[16,22]$

To analyze the thermal stability of avocado oil (OP, OM, and OE samples), thermal analyses were done in an interval of $20-700{ }^{\circ} \mathrm{C}$ in an oxidant atmosphere. The TG/DTG curves are shown in Figure 3. The observed thermal degradation for OP, OM, and OE occurred in five and six steps of degradation. The TG-plateau of for the OP and OM and OE samples showed differences in the maximum degradation temperatures of the different step-thermal behavior.
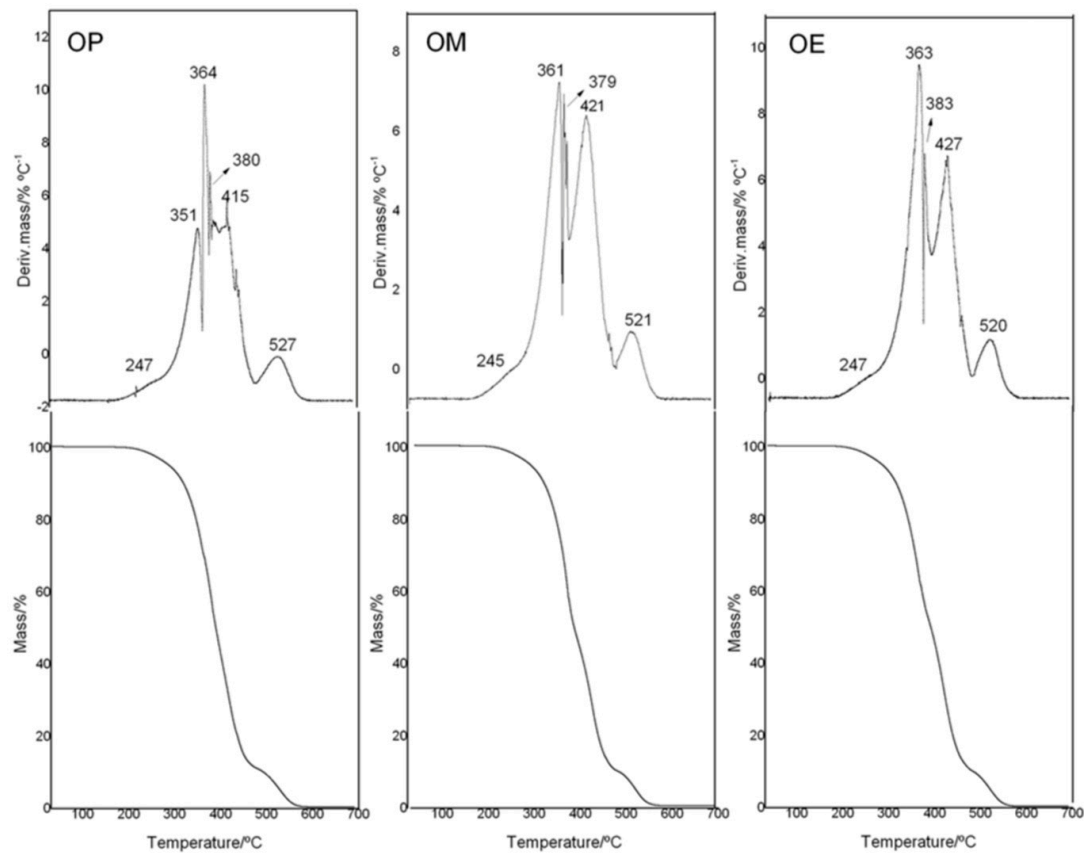

Figure 3. TG/DTG curves of avocado oil (OP), and avocado oil fortified with methanolic (OM) and ethyl ether (OE) extracts of maqui leaves.

The onset temperature of mass loss (Tonset $/{ }^{\circ} \mathrm{C}$ ) (Table 3) for OP and OE were similar with a value of $233-234{ }^{\circ} \mathrm{C}$, while $\mathrm{OM}$ (Tonset $/{ }^{\circ} \mathrm{C}$ : 240) had an increase of $\approx 7{ }^{\circ} \mathrm{C}$ with respect to $\mathrm{OP}$ and $\mathrm{OE}$.

Table 3. Thermal decomposition temperatures of OP, OM, and OE avocado oils.

\begin{tabular}{ccccc}
\hline & \multicolumn{4}{c}{ Temperature $\left({ }^{\circ} \mathbf{C}\right)$ Corresponding to } \\
\cline { 2 - 5 } Oil & $\boldsymbol{T}_{\text {onset }} /{ }^{\circ} \mathbf{C}^{\mathbf{a}}$ & $\boldsymbol{T}_{\mathbf{5}} /{ }^{\circ} \mathbf{C}^{\mathbf{b}}$ & $\boldsymbol{T}_{\mathbf{1 0}} /{ }^{\circ} \mathbf{C}^{\mathbf{c}}$ & $\boldsymbol{T}_{\mathbf{5 0}} /{ }^{\circ} \mathbf{C}^{\mathbf{d}}$ \\
\hline OP & 234 & 288 & 319 & 389 \\
OE & 233 & 286 & 315 & 391 \\
OM & 240 & 292 & 321 & 386 \\
\hline
\end{tabular}

Decomposition temperature $\left({ }^{\circ} \mathrm{C}\right):{ }^{\text {a }}$ onset temperature, ${ }^{\mathrm{b}}$ at $5 \%$ mass loss, ${ }^{\mathrm{c}}$ at $10 \%$ mass loss, ${ }^{\mathrm{d}}$ at $50 \%$ mass loss. 
With a mass loss of 5,10 , and 50\%, the temperature of degradation for OP oil was found to be at 288,319 , and $389^{\circ} \mathrm{C}$, respectively, while $\mathrm{OE}$ presents values of 286,315 , and $391{ }^{\circ} \mathrm{C}$, with a decrease being observed around $2-4{ }^{\circ} \mathrm{C}$ at 5 and $10 \%$ of mas loss and only an increase of $3{ }^{\circ} \mathrm{C}$ at $50 \%$ of mass loss for no-enriched OP. On the other hand, OM oil showed high temperature displacements to $6^{\circ} \mathrm{C}$ for 5 and $10 \%$ of mass loss in comparison with OP oil. Our research group reported similar results as those by a study related to the effect of eugenol as an additive used in essential oils of Hedychium coronarium J. Koening (Zingiberaceae). The results showed an increase of $12{ }^{\circ} \mathrm{C}$ at the supplementation of $4.7 \%$ $(v / v)$ for $\mathrm{T} 20 \% /{ }^{\circ} \mathrm{C}[55]$. The ability to enhance the thermal stability of the methanol extract from maqui leaves in avocado oil is no surprise since that OM is fifty and four times greater than that of the $\mathrm{OE}$ as far as its phenol composition and antioxidant activity are concerned (Table 2). These results are related to the higher affinity of the antioxidant compounds for the solvent of greater polarity, which is in accordance with the total phenolic content for each extract.

In relation to the thermal stability of avocado oil, it has recently been reported that the first step of thermal decomposition (I) was observed between $230-286{ }^{\circ} \mathrm{C}$, with the maximum temperature at $308{ }^{\circ} \mathrm{C}$ and $38.2 \%$ of mass loss. In the second step of decomposition (II), both the avocado oil suffered considerable mass losses (34.3\%) [56].

It is important to note that, although OM oil has a higher content of phenolic compounds than OE oil, the thermal behavior was not significant different. A similar trend has been reported in different studies where the effect of phenolic content of different edible oils and the relationship with their thermal behavior have been analyzed $[10,11,44]$. It is known that phenolic compounds, together with tocopherols ( $\alpha$ and $\beta$ ), contribute to the oxidative stability of edible oils [57]. However, the OM oil could be low in tocopherols. Therefore, the presence of other phenolic compounds would explain the antioxidant activity, such as gallic acid, catechin, rutin, and $p$-coumaric acids, among other [50,58].

It has been reported that avocado oils has a predicted shelf life of 210 days at $25^{\circ} \mathrm{C}$ [59]. However, its shelf life can be affected by exposure to light and high temperatures.

In order to protect edible oils from oxidation, Jiménez at al. (2017) reported the effects of hydroalcoholic extracts of olive leaves (OHE) on the thermal stability of canola oil (CO) and high oleic sunflower oil (HOSO) of French potatoes frying at $180{ }^{\circ} \mathrm{C}$. The addition of $\mathrm{OHE}$ to $\mathrm{CO}$ and $\mathrm{HOSO}$ decreased the polar compounds formation, which could be attributed to the protective action of polyphenols as oleuropein and its derivatives, oleuroside and oleuroside-10-carboxylic acid $[49,60]$. Other edible oils, such as coconut and avocado oils, have been fortified with hydroxycinnamic acids such as caffeic (CA) and p-coumaric (pCA) acids. The hydroxycinnamic fortification (300 ppm; premixed with PEG $(3 \%, w / w))$ of both oils were stored at 20 and $60{ }^{\circ} \mathrm{C}$ for 50 days, and oxidation parameters were monitored, namely, peroxide values, $\mathrm{p}$-anisidine value, and free fatty acids, among other. The results showed that the oxidation process was accelerated when samples were stored at $60{ }^{\circ} \mathrm{C}$. However, CA and pCA helped preserve avocado and coconut oils from oxidation [50]. Similar results have been described for avocado oil fortified with phlorizin (dihydrochalcone) encapsulated with alginate, in the study for improving the oxidative stability and suppressing hydrolytic rancidity of avocado oil at $37^{\circ} \mathrm{C}$ [51].

Despite the possible differences in the composition of phenolic compounds in $\mathrm{OE}$ and OM oil previously described, the difference of LogP and ESOL solubility of the different phenolic compounds (Table 4) play an important role in the triglyceride hydrophobic interaction of phenolic compounds and avocado oil. The hydrophobic interaction of $\alpha$ and $\beta$-tocopherol $(\log P: 8.27(\alpha) ; 7.79(\beta))$ in OE was greater than that shown by gallic acid (LogP: 0.21), catechin (LogP: 0.83), rutin (LogP: -1.12), and p-cumaric acid (LogP: 1.26) in OM.

This would explain that even though the number of phenolic compounds in $\mathrm{EO}$ is fifty times lower than in OM, Tocopherols present in OE had a higher LogP values than phenols contained in $\mathrm{OM}$, maintaining good protection. 
Table 4. LogP and estimating aqueous solubility directly from the molecular structure (ESOL) from phenols compounds present in maqui leaves.

\begin{tabular}{cccccc}
\hline Compound & MW & Consensus LogP & ESOL Log S $^{\mathbf{b}}$ & ESOL Solubility (mol/L) $^{\mathbf{c}}$ & ESOL Class $^{\text {ES }}$ \\
\hline$\alpha$-tocopherol & 430.71 & 8.27 & -8.60 & $2.50 \times 10^{-9}$ & Poorly soluble \\
$\beta$-tocopherol & 416.68 & 7.79 & -8.29 & $5.16 \times 10^{-9}$ & Poorly soluble \\
Gallic acid & 170.12 & 0.21 & -1.64 & $2.29 \times 10^{-2}$ & Very soluble \\
Catechin & 290.27 & 0.83 & -2.22 & $5.98 \times 10^{-3}$ & Soluble \\
Rutin & 610.52 & -1.12 & -3.30 & $5.05 \times 10^{-4}$ & Soluble \\
$p$-cumaric acid & 164.16 & 1.26 & -2.02 & $9.65 \times 10^{-3}$ & Soluble \\
\hline
\end{tabular}

a,b,c LogP and ESOL parameters were computed using the freely accessible web server SwissADME: http://swissadme.ch/index.php\# (accessed on 20 January 2021) undefined.

The results of this last analysis are corroborated by the index of polar compounds. This index is considered a robust indicator to describe the deterioration of fatty material because it involves the degradation products of triacylglyceride.

According to Figure $4 \mathrm{~A}$, the index of polar compounds is increasing for the three curves (OP, OE, and $\mathrm{OM})$. However, after heating $144 \mathrm{~h}$, there is a significant difference in the content of polar compounds. Thus, the OP oil showed a percentage of polar compounds with significant differences at $144 \mathrm{~h}\left(15.16 \pm 0.29,{ }^{* * *} p<0.001\right)$, with respect to $\mathrm{OE}$ and $\mathrm{OM}$ oils (Figure 4B).
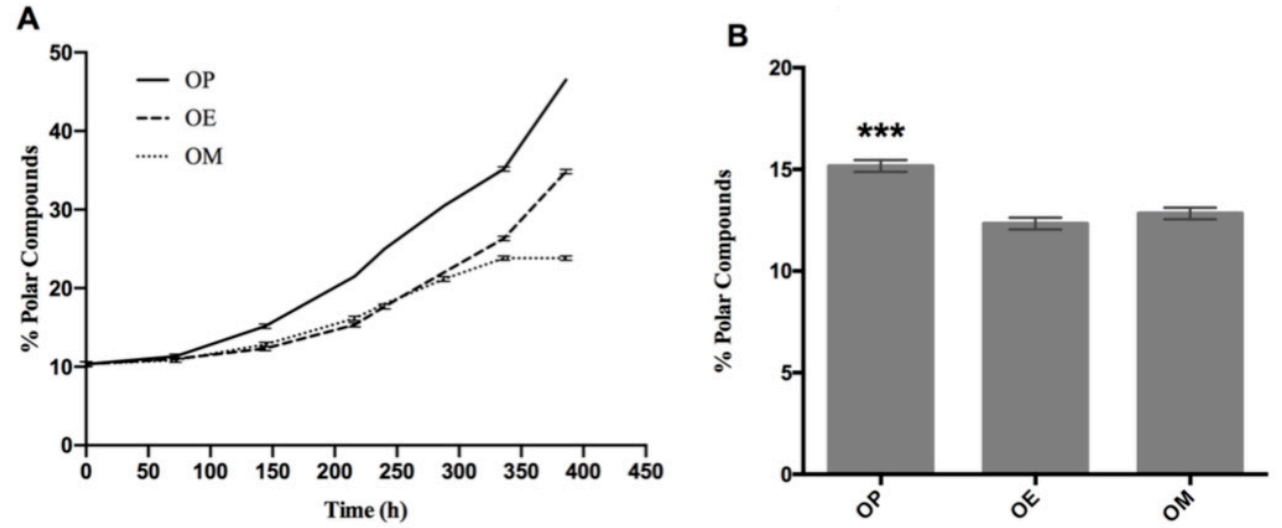

Figure 4. Evolution of total polar compounds during the thermo-oxidation of avocado oil (OP), avocado oil fortified with methanol (OM) and ethyl ether (OE) extract of maqui leaves. (A) polar content as time increases, (B) statistical analysis of the polar content at 144 and $336 \mathrm{~h}$. OP: avocado oil. *** $p<0.001$, with respect to $\mathrm{OE}$ and OM oils.

Overall, OP continues with a sustained increase above the OE and OM curves. Finally, the $\mathrm{OE}$ and $\mathrm{OM}$ curves show a separation at $288 \mathrm{~h}(p<0.05 ; p=0.01)$. On the other hand, $\mathrm{OP}$ continues with an increase rate above $\mathrm{OE}$ and $\mathrm{OM}$, with significant differences at $336 \mathrm{~h}$ $\left(35.20 \pm 0.29,{ }^{* * * *} p<0,0001\right)$ with respect to OE and OM with \%polar compounds of $26.3 \pm 0.29$ and $23.8 \pm 0.29$, respectively. A decrease of 25 and $32 \%$ was observed in the $\mathrm{OE}$ and $\mathrm{OM}$ oils, respectively, with the methanol extract of maqui leaves being more effective in antioxidant protection. This trending is observed across the different oxidation level measurements performed. Finally, OP and OE continue to increase until the end of the experiment $(386 \mathrm{~h})$, while OM maintains constant polar compounds levels.

The index of polar compounds is recognized as a parameter for quality control in different regulations in the world. In this case, it indicates that an oil destined for a thermo-oxidative process, such as the deep fat frying process, cannot exceed a value of $25 \%$ [61]. Thus, the OP, OE, and OM samples reached this value at approximately 250, 310, and $360 \mathrm{~h}$ after heating, respectively, which demonstrates the protective effect of maqui leaves extracts. 
According to this study, there is a lower production of lipid degradation compounds, when the extracts of maqui leaves are present. This protective effect could benefit other oils of great interest to the health of the population due to their high PUFA content, with oils such as grapeseed oil (66-75\% in linoleic acid) obtained from by-products of the wine industry, of great nutritional interest. Grapeseed oil has been related to anti-inflammatory properties, cardio-protective, antimicrobial, and anticancer [62]. Additionally, there are other oils with a high PUFA content along with other components of nutritional interest, such as cotton, chia, or sesame oils, which could benefit from the antioxidant fortification from natural extracts $[63,64]$. However, more studies are needed to elucidate the possible protective effects of native plant extracts.

\section{Conclusions}

Avocado oil has different fatty acids and naturally occurring antioxidant components that protect the oil against thermo-oxidative deterioration. Fortification with maqui leaves extracts using two solvent improves the thermo-oxidative stability of the pure oil, demonstrating a beneficial effect for avocado oil. The methanolic extract has a better protective effect on the thermo-oxidation of the oil after heating for $336 \mathrm{~h}$. In addition, secondary oxidation products demonstrate a marked difference between the fortified and non-fortified samples after $144 \mathrm{~h}$ of heating. By using solvents of different polarity, the antioxidant properties of plant extracts of $A$. chilensis leaves can be improved. Despite the maqui leaf extract's well-known and verified positive effect on health, new in vitro and in vivo studies, focused mainly on the toxicity and hormetic role of the antioxidant compounds of maqui leaves, should be carried out in the future before its secure application as a food additive. Finally, the use of by-products from native plants, such as leaves, can be an alternative to the addition of non-natural compounds in oils.

Author Contributions: Conceptualization, M.F., J.E., and O.F.-D.; methodology, J.O.-V., N.R., and Y.V.; software, M.F., L.R.-G., and J.O.-V.; validation, N.R., Y.V., and C.R.; formal analysis, L.R.G., J.O.-V., and C.R.; investigation, M.F. N.R., Y.V., and O.F.-D.; resources, M.F. and J.O.-V.; data curation, L.R.-G., J.E., and O.F.-D.; writing — original draft preparation, M.F., J.E. and O.F.-D.; writingreview and editing, M.F., C.R., and O.F.-D.; visualization, M.F. and C.R.; supervision, M.F.; project administration, M.F.; funding acquisition, M.F. All authors have read and agreed to the published version of the manuscript.

Funding: This research received no external funding.

Institutional Review Board Statement: Not applicable.

Informed Consent Statement: Not applicable.

Data Availability Statement: The data presented in this study are available on request from the corresponding author.

Acknowledgments: The authors O.F.-D. and J.E. acknowledge the financial support of Projects: DICYT-USACH 022041_EM Postdoctoral and CONICYT PAI/ACADEMIA N ${ }^{\circ} 79160109$.

Conflicts of Interest: The authors declare no conflict of interest.

\section{References}

1. Flores, M.; Saravia, C.; Vergara, C.E.; Avila, F.; Valdés, H.; Ortiz-Viedma, J. Avocado oil: Characteristics, properties, and applications. Molecules 2019, 24, 2172. [CrossRef]

2. Ozdemir, F; Topuz, A. Changes in dry matter, oil content and fatty acids composition of avocado during harvesting time and post-harvesting ripening period. Food Chem. 2004, 86, 79-83. [CrossRef]

3. Espinosa-Alonso, L.G.; Paredes-López, O.; Valdez-Morales, M.; Oomah, B.D. Avocado oil characteristics of Mexican creole genotypes. Eur. J. Lipid Sci. Technol. 2017, 119, 1600406. [CrossRef]

4. Yanty, N.A.M.; Marikkar, J.M.N.; Long, K. Effect of varietal differences on composition and thermal characteristics of avocado oil. J. Am. Oil Chem. Soc. 2011, 88, 1997-2003. [CrossRef]

5. Green, H.S.; Wang, S.C. First report on quality and purity evaluations of avocado oil sold in the US. Food Control 2020, 107328. [CrossRef] 
6. Farines, M.; Soulier, J.; Rancurel, A.; Montaudoin, M.G.; Leborgne, L. Influence of avocado oil processing on the nature of some unsaponifiable constituents. J. Am. Oil Chem. Soc. 1995, 72, 473-476. [CrossRef]

7. Li, J.; Bi, Y.; Sun, S.; Peng, D. Simultaneous analysis of tert-butylhydroquinone, tert-butylquinone, butylated hydroxytoluene, 2-tert-butyl-4-hydroxyanisole, 3-tert-butyl-4-hydroxyanisole, $\alpha$-tocopherol, $\gamma$-tocopherol, and $\delta$-tocopherol in edible oils by normal-phase high performance liquid. Food Chem. 2017, 234, 205-211. [CrossRef]

8. Saad, B.; Sing, Y.Y.; Nawi, M.A.; Hashim, N.; Mohamed Ali, A.S.; Saleh, M.I.; Sulaiman, S.F.; Talib, K.M.; Ahmad, K. Determination of synthetic phenolic antioxidants in food items using reversed-phase HPLC. Food Chem. 2007, 105, 389-394. [CrossRef]

9. Xu, X.; Liu, A.; Hu, S.; Ares, I.; Martínez-Larrañaga, M.-R.; Wang, X.; Martínez, M.; Anadón, A.; Martínez, M.-A. Synthetic phenolic antioxidants: Metabolism, hazards and mechanism of action. Food Chem. 2021, 353, 129488. [CrossRef]

10. Forero-Doria, O.; García, M.F.; Vergara, C.E.; Guzman, L. Thermal analysis and antioxidant activity of oil extracted from pulp of ripe avocados. J. Therm. Anal. Calorim. 2017, 130. [CrossRef]

11. Forero-Doria, O.; Gallego, J.; Valdes, O.; Pinzon-Topal, C.; Santos, L.S.; Guzmán, L. Relationship between oxidative stability and antioxidant activity of oil extracted from the peel of Mauritia flexuosa fruits. J. Therm. Anal. Calorim. 2016, 123. [CrossRef]

12. Berasategi, I.; Barriuso, B.; Ansorena, D.; Astiasarán, I. Stability of avocado oil during heating: Comparative study to olive oil. Food Chem. 2012, 132, 439-446. [CrossRef] [PubMed]

13. Flores, M.; Ortiz-Viedma, J.; Romero, N.; Masson, L.; Robert, P.; Garcia, P. Effect of Rosa Mosqueta Husk Extract (Rosa rubiginosa) on Thermooxidation of Grape Seed Oil. J. Food Qual. 2019, 2019, 8464670. [CrossRef]

14. Anwar, F.; Qayyum, H.M.A.; Hussain, A.I.; Iqbal, S. Actividad antioxidante de extractos de metanol al $80 \%$ y al $100 \%$ de semillas de cebada (Hordeum vulgare L.): Estabilización del aceite de girasol. Grasas y Aceites 2010, 61, 237-243. [CrossRef]

15. Nour, V.; Corbu, A.R.; Rotaru, P.; Karageorgou, I.; Lalas, S. Effect of carotenoids, extracted from dry tomato waste, on the stability and characteristics of various vegetable oils. Grasas y Aceites 2018, 69, 238. [CrossRef]

16. Rubilar, M.; Jara, C.; Poo, Y.; Acevedo, F.; Gutierrez, C.; Sineiro, J.; Shene, C. Extracts of Maqui (Aristotelia chilensis) and Murta (Ugni molinae Turcz.): Sources of antioxidant compounds and $\alpha$-Glucosidase/ $\alpha$-Amylase inhibitors. J. Agric. Food Chem. 2011, 59, 1630-1637. [CrossRef]

17. Ávila, F.; Jiménez-Aspee, F.; Cruz, N.; Gómez, C.; González, M.A.; Ravello, N. Additive effect of maqui (Aristotelia chilensis) and lemon (Citrus $x$ limon) juice in the postprandial glycemic responses after the intake of high glycemic index meals in healthy men. NFS J. 2019, 17, 8-16. [CrossRef]

18. Genskowsky, E.; Puente, L.A.; Pérez-Álvarez, J.A.; Fernandez-Lopez, J.; Muñoz, L.A.; Viuda-Martos, M. Assessment of antibacterial and antioxidant properties of chitosan edible films incorporated with maqui berry (Aristotelia chilensis). LWT-Food Sci. Technol. 2015, 64, 1057-1062. [CrossRef]

19. Fredes, C.; Osorio, M.J.; Parada, J.; Robert, P. Stability and bioaccessibility of anthocyanins from maqui (Aristotelia chilensis [Mol.] Stuntz) juice microparticles. LWT 2018, 91, 549-556. [CrossRef]

20. Muñoz, O.; Christen, P.; Cretton, S.; Backhouse, N.; Torres, V.; Correa, O.; Costa, E.; Miranda, H.; Delporte, C. Chemical study and anti-inflammatory, analgesic and antioxidant activities of the leaves of Aristotelia chilensis (Mol.) Stuntz, Elaeocarpaceae. J. Pharm. Pharmacol. 2011, 63, 849-859. [CrossRef]

21. Pacheco, P.; Sierra, J.; Schmeda-Hirschmann, G.; Potter, C.W.; Jones, B.M.; Moshref, M. Antiviral activity of Chilean medicinal plant extracts. Phyther. Res. 1993, 7, 415-418. [CrossRef]

22. Suwalsky, M.; Vargas, P.; Avello, M.; Villena, F.; Sotomayor, C.P. Human erythrocytes are affected in vitro by flavonoids of Aristotelia chilensis (Maqui) leaves. Int. J. Pharm. 2008, 363, 85-90. [CrossRef] [PubMed]

23. Alizadeh, L.; Abdolmaleki, K.; Nayebzadeh, K.; Shahin, R. Effects of tocopherol, rosemary essential oil and Ferulago angulata extract on oxidative stability of mayonnaise during its shelf life: A comparative study. Food Chem. 2019, 285, 46-52. [CrossRef]

24. Chun, S.-S.; Vattem, D.A.; Lin, Y.-T.; Shetty, K. Phenolic antioxidants from clonal oregano (Origanum vulgare) with antimicrobial activity against Helicobacter pylori. Process Biochem. 2005, 40, 809-816. [CrossRef]

25. Dávalos, A.; Gómez-Cordovés, C.; Bartolomé, B. Extending applicability of the oxygen radical absorbance capacity (ORACfluorescein) assay. J. Agric. Food Chem. 2004, 52, 48-54. [CrossRef] [PubMed]

26. International Union of Pure and Applied Chemistry (IUPAC). Standard Methods for the Analysis of Oils, Fats and Derivatives, Part 1, 6th ed.; International Union of Pure and Applied Chemistry (IUPAC): Research Triangle Park, NC, USA, 1979; pp. 96-108.

27. Paz Antolín, I.; Molero Meneses, M. Aplicación de la espectrofotometría UV-visible al estudio de la estabilidad térmica de aceites vegetales comestibles. Grasas y Aceites 2000, 51, 424-428.

28. Fatemi, S.H.; Hammond, E.G. Analysis of oleate, linoleate and linolenate hydroperoxides in oxidized ester mixtures. Lipids 1980, 15, 379-385. [CrossRef]

29. Abril, D.; Mirabal-Gallardo, Y.; González, A.; Marican, A.; Durán-Lara, E.F.; Silva Santos, L.; Valdés, O. Comparison of the oxidative stability and antioxidant activity of extra-virgin olive oil and oils extracted from seeds of Colliguaya integerrima and Cynara cardunculus under normal conditions and after thermal treatment. Antioxidants 2019, 8, 470. [CrossRef] [PubMed]

30. Esmat, A.Y.; Hassan, R.E.; Abo-ElWafa, G.A.; Abou-ElSoud, M.M.; Megahed, M.G. Physicochemical characteristics and oxidative stability of Egyptian corn germ oil produced by aqueous enzymatic extraction. Grasas y Aceites 2018, 69, 275. [CrossRef]

31. Firestone, D. Physical and Chemical Characteristics of Oils, Fats, and Waxes; Aocs Press: Urbana, IL, USA, 2006 ; ISBN 1893997995.

32. Omonov, T.S.; Kharraz, E.; Curtis, J.M. The epoxidation of canola oil and its derivatives. RSC Adv. 2016, 6, 92874-92886. [CrossRef]

33. Paganuzzi, V.; Leoni, E. On the composition of Iranian olive oil. J. Am. Oil Chem. Soc. 1979, 56, 925-930. [CrossRef] 
34. Orsavova, J.; Misurcova, L.; Ambrozova, J.V.; Vicha, R.; Mlcek, J. Fatty acids composition of vegetable oils and its contribution to dietary energy intake and dependence of cardiovascular mortality on dietary intake of fatty acids. Int. J. Mol. Sci. 2015, 16, 12871-12890. [CrossRef]

35. Kobelnik, M.; Cassimiro, D.L.; dos Santos Dias, D.; Ribeiro, C.A.; Crespi, M.S. Thermal behavior of jerivá oil (Syagrus romanzoffiana). J. Therm. Anal. Calorim. 2011, 106, 711-715. [CrossRef]

36. Kobelnik, M.; Cassimiro, D.L.; dos Santos Dias, D.; Ribeiro, C.A.; Crespi, M.S. Thermal behavior of araça oil (Psidium cattleianum Sabine). J. Therm. Anal. Calorim. 2012, 108, 1281-1286. [CrossRef]

37. Kobelnilk, M.; Fontanari, G.G.; Cassimiro, D.L.; Ribeiro, C.A.; Crespi, M.S. Thermal behavior of coffee oil (Robusta and Arabica species). J. Therm. Anal. Calorim. 2014, 115, 2045-2052. [CrossRef]

38. Ferreira, B.S.; De Almeida, C.G.; Faza, L.P.; De Almeida, A.; Diniz, C.G.; Silva, V.L.d.; Grazul, R.M.; Le Hyaric, M. Comparative properties of amazonian oils obtained by different extraction methods. Molecules 2011, 16, 5875-5885. [CrossRef] [PubMed]

39. Woolf, A.; Wong, M.; Eyres, L.; McGhie, T.; Lund, C.; Olsson, S.; Wang, Y.; Bulley, C.; Wang, M.; Friel, E. Avocado oil. In Gourmet and Health-Promoting Specialty Oils; Elsevier: Amsterdam, The Netherlands, 2009; pp. 73-125.

40. Flores, M.A.; Perez-Camino, M.D.C.; Troca, J. Preliminary studies on composition, quality and oxidative stability of commercial avocado oil produced in Chile. J. Food Sci. Eng. 2014, 4, 21.

41. Canvin, D.T. The effect of temperature on the oil content and fatty acid composition of the oils from several oil seed crops. Can. J. Bot. 1965, 43, 63-69. [CrossRef]

42. Fernandes, G.D.; Gómez-Coca, R.B.; Pérez Camino, M.d.C.; Moreda, W.; Barrera-Arellano, D. Chemical characterization of commercial and single-variety avocado oils. Grasas y Aceites 2018, 69, e256. [CrossRef]

43. Santos, J.C.O.; Dos Santos, I.M.G.; De Souza, A.G.; Prasad, S.; Dos Santos, A.V. Thermal stability and kinetic study on thermal decomposition of commercial edible oils by thermogravimetry. J. Food Sci. 2002, 67, 1393-1398. [CrossRef]

44. Flores García, M.; Vergara, C.E.; Forero-Doria, O.; Guzman, L.; Perez-Camino, M.C. Chemical evaluation and thermal behavior of Chilean hazelnut oil (Gevuina avellana Mol) a comparative study with extra virgin olive oil. Eur. Food Res. Technol. 2019, 245. [CrossRef]

45. Lewis-McCrea, L.M.; Lall, S.P. Effects of moderately oxidized dietary lipid and the role of vitamin E on the development of skeletal abnormalities in juvenile Atlantic halibut (Hippoglossus hippoglossus). Aquaculture 2007, 262, 142-155. [CrossRef]

46. Grajeda-Iglesias, C.; Salas, E.; Barouh, N.; Baréa, B.; Panya, A.; Figueroa-Espinoza, M.C. Antioxidant activity of protocatechuates evaluated by DPPH, ORAC, and CAT methods. Food Chem. 2016, 194, 749-757. [CrossRef] [PubMed]

47. Resende, L.M.B.; de Souza, V.R.; Ferreira, G.M.D.; Nunes, C.A. Changes in quality and phytochemical contents of avocado oil under different temperatures. J. Food Sci. Technol. 2019, 56, 401-408. [CrossRef] [PubMed]

48. Prescha, A.; Grajzer, M.; Dedyk, M.; Grajeta, H. The antioxidant activity and oxidative stability of cold-pressed oils. J. Am. Oil Chem. Soc. 2014, 91, 1291-1301. [CrossRef] [PubMed]

49. Jiménez, P.; García, P.; Bustamante, A.; Barriga, A.; Robert, P. Thermal stability of oils added with avocado (Persea americana cv. Hass) or olive (Olea europaea cv. Arbequina) leaf extracts during the French potatoes frying. Food Chem. 2017, 221, 123-129. [CrossRef] [PubMed]

50. Sun-Waterhouse, D.; Thakorlal, J.; Zhou, J. Effects of added phenolics on the storage stability of avocado and coconut oils. Int. J. food Sci. Technol. 2011, 46, 1575-1585. [CrossRef]

51. Sun-Waterhouse, D.; Penin-Peyta, L.; Wadhwa, S.S.; Waterhouse, G.I.N. Storage stability of phenolic-fortified avocado oil encapsulated using different polymer formulations and co-extrusion technology. Food Bioprocess Technol. 2012, 5, 3090-3102. [CrossRef]

52. Brand, M.H.; Connolly, B.A.; Levine, L.H.; Richards, J.T.; Shine, S.M.; Spencer, L.E. Anthocyanins, total phenolics, ORAC and moisture content of wild and cultivated dark-fruited Aronia species. Sci. Hortic. 2017, 224, 332-342. [CrossRef]

53. Muñoz, O.; Ramos, F. Quantitative analysis of phytosterols in Aristotelia chilensis (Maqui) leaves using GC/MS. Int. Food Res. J. 2016, 23, 822-826.

54. Vidal, J.L.; Avello, L.M.; Loyola, C.C.; Campos, P.J.; Aqueveque, M.P.; Dungan, R.S.; Galotto, L.M.; Guarda, M.A. A Microencapsulation of maqui (Aristotelia chilensis Molina Stuntz) leaf extracts to preserve and control antioxidant properties. Chil. J. Agric. Res. 2013, 73, 17-23. [CrossRef]

55. Macias, J.P.J.; Castro, R.I.; Esguerra, S.K.G.; Marin, J.G.; Guzman, L.; Gutierrez, M.; Vergara, C.E.; Forero-Doria, O. Eugenol supplementation as an additive to improve the thermal stability of Hedychium coronarium Koening essential oil. Nat. Prod. J. 2020, 10. [CrossRef]

56. Castro, R.I.; Gallego, J.; García, M.F.; Marican, A.; Forero-Doria, O. Thermal study and composition of edible oils combined by TG/DTG analysis through predictive statistical model. J. Therm. Anal. Calorim. 2020. [CrossRef]

57. Franco, M.N.; Galeano-Díaz, T.; Sánchez, J.; De Miguel, C.; Martín-Vertedor, D. Total phenolic compounds and tocopherols profiles of seven olive oil varieties grown in the south-west of Spain. J. Oleo Sci. 2014, 63, 115-125. [CrossRef]

58. Rodríguez, K.; Ah-Hen, K.S.; Vega-Gálvez, A.; Vásquez, V.; Quispe-Fuentes, I.; Rojas, P.; Lemus-Mondaca, R. Changes in bioactive components and antioxidant capacity of maqui, Aristotelia chilensis [Mol] Stuntz, berries during drying. LWT Food Sci. Technol. 2016, 65, 537-542. [CrossRef]

59. Aktar, T.; Adal, E. Determining the Arrhenius kinetics of avocado oil: Oxidative stability under rancimat test conditions. Foods 2019, 8, 236. [CrossRef] 
60. Jimenez, P.; Masson, L.; Barriga, A.; Chávez, J.; Robert, P. Oxidative stability of oils containing olive leaf extracts obtained by pressure, supercritical and solvent-extraction. Eur. J. Lipid Sci. Technol. 2011, 113, 497-505. [CrossRef]

61. Flores, M.; Meyer, L.; Orellana, S.; Saravia, C.; Galdames, C.; Perez-Camino, M.C. Quality of Lipid Fractions in Deep-Fried Foods from Street Vendors in Chile. J. Food Qual. 2018, 2018, 7878439. [CrossRef]

62. Garavaglia, J.; Markoski, M.M.; Oliveira, A.; Marcadenti, A. Grape seed oil compounds: Biological and chemical actions for health. Nutr. Metab. Insights 2016, 9, NMI-S32910. [CrossRef] [PubMed]

63. Lutterodt, H.; Slavin, M.; Whent, M.; Turner, E.; Yu, L.L. Fatty acid composition, oxidative stability, antioxidant and antiproliferative properties of selected cold-pressed grape seed oils and flours. Food Chem. 2011, 128, 391-399. [CrossRef]

64. Misajel, K.A.; Gutiérrez, M.G.; Rodríguez, C.M.; Escudero, F.R. Organically vs conventionally-grown dark and white chia seeds (Salvia hispanica L.): Fatty acid composition, antioxidant activity and techno-functional properties. Grasas y Aceites $2019,70,3$. 